\title{
Intravitreal Bevacizumab to Treat Retinopathy of Prematurity in 865 Eyes: a Study to Determine Predictors of Primary Treatment Failure and Recurrence
}

\section{Kaveh Fadakar}

Farabi Eye Hospital

Mohammadreza Mehrabi Bahar ( $\nabla$ mreza.mehrabibahar@gmail.com )

Farabi Eye Hospital https://orcid.org/0000-0001-8829-053X

Hamid Riazi-Esfahani

Farabi Eye Hospital

Afsaneh Azarkish

Farabi Eye Hospital

Afsar Dastjani Farahani

Farabi Eye Hospital

Mostafa Heidari

Farabi Eye Hospital

Fatemeh Bazvand

Farabi Eye Hospital

\section{Research Article}

Keywords: Retinopathy of prematurity, Intravitreal Bevacizumab, Regression, Treatment failure, Recurrence

Posted Date: September 9th, 2021

DOl: https://doi.org/10.21203/rs.3.rs-876613/v1

License: (c) (1) This work is licensed under a Creative Commons Attribution 4.0 International License. Read Full License 


\section{Abstract}

Purpose: This study aimed To evaluate the rate and risk factors for primary failure and recurrence after intravitreal anti-VEGF injection in retinopathy of prematurity (ROP).

Methods: This retrospective study was performed on 865 eyes from 441 patients with retinopathy of prematurity receiving intravitreal Bevacizumab from 2012 to 2019. Medical records of patients were evaluated.

Results: Mean gestational age (GA) and birth weight of patients were $28 \pm 2$ weeks and $1121 \pm 312 \mathrm{~g}$, respectively. Thirty-five eyes (4.04\%) had a primary failure, including 18 eyes from 187 eyes in zone 1 (9.6\%) and 17 eyes from 678 eyes in zone $2(2.5 \%)$. The mean time of retreatment was $16.64 \pm 13.68$ days in eyes without regression ROP. The remaining 830 eyes (95.95\%) were included in recurrence analysis. The recurrence occurred in 33 eyes (3.97\%) of them in 20 patients, with the meantime of 77.52 days after the first treatment (IVB). Presence of plus disease, history of oxygen therapy or phototherapy, and GA less than 32 were associated with significantly increased prevalence of treatment failure. The risk factor predicting recurrence are lower birth weight, zone 1 pretreatment, history of intubation, anemia, and sepsis.

Conclusion: Intravitreal anti-VEGF is a successful treatment for ROP with a low rate of primary failure and recurrence. Attention to risk factors accompanied by special care to patterns of treatment failure and recurrence helps to achieve early detection of treatment failure and vigilant follow up for recurrence.

\section{Introduction}

Retinopathy of prematurity (ROP) is a vasoproliferative disease of the immature retina and one of the major preventable causes of childhood blindness. ${ }^{1}$ Preterm delivery caused inhibition of physiologic retinal vascular development and led to the persistent avascular retina, and the pathologic vasoproliferation in some severe cases of ROP caused advanced stages, which may require treatment. ${ }^{2}$ Laser ablation of the retina's avascular area is the mainstay of treatment for many years; it significantly reduced unfavorable outcomes. ${ }^{3}$ Nonetheless, its side effect like permanent destruction of the peripheral retina, visual field loss, and induced myopia remain a concern. Since BEAT-ROP study, there is an increasing trend toward less invasive intravitreal injection of anti-VEGF drugs like Bevacizumab and Ranibizumab, especially zone $1 .{ }^{4,5}$ Anti-VEGF treatment will result in more rapid regression of abnormal vessels and more feasible in the eyes with rigid pupils and lower chance of unfavorable outcomes in type 1 ROP like high myopia. ${ }^{6,7}$ Furthermore, anti-VEGF administration are less cumbersome to deliver in comparison to standard laser treatment, as long as it let the immature retina continue its vascular development, but side effects remain a big concern. ${ }^{8,9}$

Despite the advantages mentioned above, the existence of avascular retina is a double edge in anti-VEGF treated patients instead of destruction in laser treatment. It can cause perhaps higher rate and delayed 
recurrence, as long as several studies have reported reactivation of ROP following anti-VEGF treatment known as a primary failure. Mintz-Hittner did the only randomized study to compare these modalities and report a higher and sooner rate of recurrence in laser photocoagulation compared to the IVB group, but they define recurrence in 54 weeks of postmenstrual age no longer. ${ }^{5}$ Thus, long-term follow-up remains the main challenge in anti-VEGF treatment in ROP. Different studies with different anti-VEGF

agents reported $4-18 \%$ of studied eyes, probably due to their short-lived action. ${ }^{7,10}$ ROP recurrence occurred when reappearance of the regressed ROP occurred. Due to potential long-term sequelae of the disease, and based on which anti-VEGF administration, recurrence can occur by delay in anti-VEGF monotherapy of ROP patients. ${ }^{11}$

In light of the abovementioned studies, early detection of primary failure and recurrence after intravitreal administration of anti-VEGF is essential to provide vigilant follow-up to ensure timely retreatment. We present the results of large case series of ROP-treated infants treated with intravitreal Bevacizumab to report the rate of primary failure and recurrence in these patients and the timing of recurrence. Besides, we want to assess the primary failure and recurrence risk factors to define which patients need more vigilant and examine more frequently and possibly longer follow-up.

\section{Methods}

The current study is a retrospective case series to evaluate the variables associated with primary failure and recurrence after administering intravitreal Bevacizumab for the treatment of type I ROP in zone I or II in a tertiary center Farabi Eye Hospital, Tehran, Iran. Medical documents of relevant cases were reviewed to collect data. Informed consent was obtained from the parents of the participants. The ethics committee of eye research center, Farabi Eye Hospital, approved this study (https://ethics.research.ac.ir/IR.TUMS.FARABI.REC.1399.040). All procedures and interventions were inconsistent with the tenets of the Helsinki declaration.

Infants with eye diseases other than ROP, such as congenital cataracts and glaucoma, or patients with a previous treatment history were excluded from this study. Infants were examined with indirect ophthalmoscopy. All injections were performed in an operating room. Bevacizumab $0.625 \mathrm{mg} / 0.025 \mathrm{ml}$ was injected under topical anesthesia (Tetracaine $0.5 \%$ ) following prep with betadine $5 \%$. The injection was done with a 30-gauge needle. In bilateral cases, injections were performed on the same day but from different vials of Bevacizumab. All infants received chloramphenicol or gentamycin eye drops every 6 hours for three days following injection. Follow up schedule was in the following order: day one, weekly, or biweekly based on the severity of retinopathy and the longer duration based on the eye's situation.

The primary outcome was primary treatment failure and recurrence rate following IVB treatment of ROP infants. Primary failure is defined as persistence of ROP as an absence of the regression of neovascularization and plus, or lack of observing any improvement during follow-up exams based on the eye's situation. Recurrence is defined as the reappearance of any sign of plus or appearance of pathological new vessels. ${ }^{12}$ 
The persistence of vascular tortuosity in the absence of other treatment failure indicators was not considered a sign of disease activity. Once the diagnosis of treatment failure was approved by two retina specialists with expertise in the field of ROP, rescue therapy with laser photocoagulation was performed. Standard indirect laser with a wavelength of $650 \mathrm{~nm}$ and confluent or near confluent (separation with one-half of burn spot size) was applied at the avascular retinal periphery.

The secondary outcome was to assess the time to recurrence and risk factors for predicting primary failure and recurrence following treatment with intravitreal anti-VEGF agents.

\section{Statistical analysis:}

We used mean, standard deviation, median, and range, frequency, and percent to present data. Risk for primary failure is presented as prevalence ratio $(\mathrm{PR})$ with its related $95 \% \mathrm{Cl}$, which indicates the added prevalence of the outcome in the presence of the specific variable in the definite time. Because recurrence occurred in the extended time, to better present the risk of recurrence, we used Hazard Ratio (HR) with its related $95 \% \mathrm{Cl}$ from a shared frailty Cox regression model to compare the intensity of the recurrence in the different groups. Variables with a P-value less than 0.1 in this analysis entered into a shared frailty multiple Cox regression model. Then, we exclude the statistically non-significant variables using a Backward approach until there is no variable with a P-value $>0.1$ in the model. All statistical analysis performed by Stata (StataCorp. 2017. Stata Statistical Software: Release 15. College Station, TX: StataCorp LLC). $P$ value less than 0.05 was set as statistically significant effect.

\section{Results}

\section{Subjects}

In this retrospective case series, 865 eyes of 252 male (57.1\%) and 189 female (42.9\%) infants were recruited. Mean gestational age was $28 \pm 2$ weeks, with a range of 22 to 34 weeks. Patients had a mean

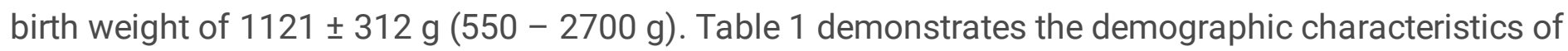
infants.

\section{Primary Failure analysis:}

Patients underwent treatment with intravitreal bevacizumab injection. Thirty-five eyes (4.04\%) had the criteria of primary failure for whom laser therapy was applied. The first time of treatment requirement was $58.83 \pm 19.19$ days (21-162) after birth. In patients with regression ROP, the meantime of regression

after receiving IVB and last follow-up were $13.72 \pm 9.55$ and $289.43 \pm 257$ days, respectively. The mean time of follow-up in patients with primary failure treatment was $419.33 \pm 529.48$ days. The rate of OD/OS was 431/434. Plus disease was observed in 861 eyes (99.5\%). The situation of zone and stage included 187 (21.6\%) zone 1, $678(78.4 \%)$ zone 2, $2(0.2 \%)$ stage 1, 33 (3.8\%) stage 2 and $830(96 \%)$ stage 3 , 
respectively. Neovascularization of iris (NVI) was observed in $54(6.2 \%)$ eyes. Primary failure of treatment was observed in 18 eyes from 187 eyes in zone 1 (9.6\%) and 17 eyes from 678 eyes in zone $2(2.5 \%)$. The mean time of retreatment was $16.64 \pm 13.68$ days in eyes without regression ROP. Retreatments included just laser in 23 eyes (65.7\%), laser and then vitrectomy in 5 eyes (14.3\%), repeated IVB and then laser in 2 eyes (5.7\%), laser and sclera buckle in one session in 2 eyes (5.7\%), just vitrectomy in 2 eyes (5.7\%), and finally, laser then repeated IVB, followed by vitrectomy in 1 eye $(2.9 \%)$.

\section{Risk factors of primary failure}

Table 2 shows the prevalence ratio of variables associated with unresponsiveness to intravitreal bevacizumab. The presence of plus disease was associated with $4 \%$ increased prevalence of treatment failure (95\% Cl: 1.022 - 1.058; P-value: <0.001). Additionally, patients who had a history of oxygen therapy or phototherapy had a greater risk of treatment failure (PR: 1.045; 95Cl\%: $1.025-1.065$; P-value: <0.001; PR: 1.039; 95\%Cl: 1.008 - 1.071; P-value: 0.014; respectively). Patients with GA less than 32 weeks had a $4.4 \%$ increased possibility of treatment failure (95\% Cl: $1.024-1.065)$; however, birth weight was not associated with a higher incidence of failure (PR: 0.99; 95\% Cl: $0.92-1.06$; P-value: 0.791).

Factors with a P value less than 0.1 were selected for multiple variable GLM model regression analysis. GA, Plus disease, history of phototherapy, and oxygen therapy still were associated with a higher rate of primary treatment failure (Table 3).

\section{Recurrence analysis:}

The recurrence occurred in 33 eyes (3.97\%) from 20 patients, with the meantime of 77.52 days after receiving the first treatment (IVB). Only 7 (35\%) of mentioned patients got the recurrence unilaterally. Characteristic findings of patients with recurrence were summarized in table 1. ROP recurred in 13 eyes (7.69\%) from whose the ROP was in zone 1 and 20 eyes (3.02\%) from whose the ROP was in zone 2 ( $p$ value: 0.008$)$. On the other hand, recurrence was more common in patients with ROP in zone 1 than in zone 2 at the time of first treatment (7.69\% vs. 3.02\%). All of the 33 eyes with recurrence had stage 3 before the second treatment.

\section{Risk factors of recurrence}

Table 4 shows the recurrence prevalence of the ROP in the infants based on the different conditions. We calculated the hazard ratio in survival analysis with its related $95 \% \mathrm{Cl}$ from a shared frailty Cox regression model to compare the recurrence rate according to compare 16 potential risk factors between recurrence and nonrecurrence eyes. The final model (the statistically significant variables) includes BW, Zone 1 pretreatment, intubation, sepsis, and anemia. Each $100 \mathrm{gr}$ increase in the BW was negatively related to 
the hazard of recurrence (HR=0.85, 95\% Cl: 0.74 to $0.99, P=0.033)$. Infants whom got intubation ( $H R=4.0$, $95 \% \mathrm{Cl}: 1.7$ to $9.5, \mathrm{P}=0.002)$, history of anemia ( $\mathrm{HR}=3.1,95 \% \mathrm{Cl}: 1.4$ to $6.6, \mathrm{P}=0.004)$, zone 1 pretreatment $(\mathrm{HR}=2.59,95 \% \mathrm{Cl}: 1.29$ to $5.21, \mathrm{P}=0.008)$ or history of sepsis $(\mathrm{HR}=2.65,95 \% \mathrm{Cl}: 1.30$ to $5.39, \mathrm{P}=0.007)$ had higher hazard for recurrence.

From 666 eyes (80.2\%) of patients with 30 weeks or lower gestational age, 30 (4.5\%) eyes have recurrent ROP. Although this number was 1 in the $31-33$ weeks group and $2(6.4 \%)$ in the 34 weeks group, the calculated HR did not significantly increase with decreasing gestational age (P-value: 0.23). Of 40 patients with documented iris neovascularization, three eyes $(7.5 \%)$ have the recurrent disease; however, it was not significantly higher than the patients without NVI (30 eyes (4.6\%), P-value: 0.47). All 33 patients with recurrent disease have a history of oxygen therapy. The HR ratio for ARDS was marginally insignificant (HR: 0.53, P-value: 0.078). Other systemic factors which we assessed in this regression model were history of sepsis, intraventricular hemorrhage, phototherapy, and being twin did not significantly increase this risk of ROP recurrence.

Factors with a P value less than 0.1 were selected for multiple variable GLM model regression analysis. Intubation is the only factor that was associated with a higher rate of recurrence (Table 6), while zone 1 pretreatment was marginally insignificant.

\section{Discussion}

ROP is a VEGF-driven vasoproliferative disease. Although retinal photocoagulation is the mainstay of ROP treatment, some authors suggest anti-VEGF agents for treating some ROP cases, like ones with media opacity, meiotic pupils, or the APROP. It has several advantages over conventional laser therapy. It is easier and less expensive without any need for expensive equipment. Also, it does not induce visual field loss which frequently occurs with laser therapy.

To our knowledge, none of the previous investigations have provided evidence regarding risk factors for primary treatment failure in patients treated initially with anti-VEGF therapy alone. Thirty-five eyes from 865 eyes treated with intravitreal bevacizumab (4.04\%) meet the criteria of primary failure. Our results demonstrated that infants with younger age and plus disease who have a history of phototherapy and oxygen therapy harbor a greater risk of treatment failure following injection of bevacizumab to treat type I ROP in zone I or II.

Nevertheless, ROP recurrence is a significant concern about anti-VEGF agents because it can devastate outcomes, like vitreoretinal traction and retinal detachment. ${ }^{13}$ Notably, it may recur after a more extended period compared with laser therapy. ${ }^{13}$ Off-label usage of Bevacizumab for regression of abnormal retinal vessels is acceptable. Its relatively large size and long half-life suggest that a single intravitreal injection may be adequate for the ROP treatment. ${ }^{5}$

In this study, we used intravitreal bevacizumab injection to treat ROP in zone 1 and zone 2. All of the 830 eyes that were treated successfully showed primary regression after receiving IVB, but ROP recurred in 33 
eyes. Thereby, intravitreal bevacizumab treatment is an effective modality in inducing regression in treatment required type $1 \mathrm{ROP}$, but recurrence is an important factor.

The art of managing IVB-treated ROP patients is to differentiate treatment failure from recurrence, chiefly because the mainstream of treatment failures signifies a misdiagnosis. ${ }^{11}$ Currently, evidence on response patterns to IVB, primary failure rate, and risk factors are scarce. Chen and colleagues described a spectrum of regression, including full vascular maturity, vascular arrest alone, or vascular arrest with persistent tortuosity following injection of bevacizumab. ${ }^{14}$ They evaluated 92 eyes of 42 infants, of whom 16 eyes (18\%) experienced reactivation. Areas of ischemia were greater in eyes with reactivation. They found younger age at IVB treatment was associated with vascular arrest accompanied by tortuosity; however, their results don't provide data about primary treatment failure.

On the other hand, recurrences need to be carefully assessed in order to avoid overtreatment. In the light of the importance of recurrence, Many studies reported the incidence of recurrences after initial treatment with intravitreal injections. The incidence of recurrence reported varies from 4 to $10 \%$. On the other hand, IVB monotherapy led to persistent avascular retina ${ }^{12,15}$ and delayed recurrence of ROP (even three years after IVB). ${ }^{16-18}$ BEAT-ROP study demonstrated a $4 \%$ risk of recurrence at a mean time of $16 \pm 4.4$ weeks post IVB injection. ${ }^{5}$ This is relatively similar to our results showing $3.9 \%$ recurrence at a mean of 18 weeks and 3 days. More recently, in a large cohort of IVB-treated ROP patients, they demonstrate, $2.5 \%$ (17 patients) failed treatment and a recurrence rate of $6.8 \%$ within the first $12 \pm 4$ weeks. ${ }^{11}$ They found initial misdiagnosis as the main culprit for unresponsiveness. However, in our study, cases of misdiagnosis are not included, and the remaining infants with primary failure have been re-examined by two experts in the field to assure correct diagnosis. Another explanation for discrepancy could be the inclusion of patients with different baseline demographic factors such as GA and birth weight which were lower in our study ( $1450 \pm 750 \mathrm{~g}$ vs. $1121 \pm 312 \mathrm{~g} ; 30 \pm 2$ weeks vs. $28 \pm 2$ weeks; respectively), as long as different ethnic.

Additionally, a lack of widely accepted criteria for practice patterns after initial treatment with IVB may lead to different approaches in various centers, which some may attain a more aggressive and cautious approach. Furthermore, Experts in ROP describe plus disease differently, but they tend to be internally consistent. ${ }^{19}$ On the other hand, other studies on ranibizumab have demonstrated an earlier and higher risk of recurrence. ${ }^{13,20}$

Some authors propose laser photocoagulation for the treatment of such recurrences, while others advocate for repeat injections. In retreatment required patients, Based on our experience, we recommend laser photocoagulation. Repeat anti-VEGF was done in cases with recurrence of retinopathy of prematurity when the border of the vascular - avascular area was posterior (posterior zone 2).

In terms of primary failure, Our results demonstrated that younger age and plus disease, history of phototherapy, and oxygen therapy harbor a greater risk following injection of bevacizumab to treat type I ROP in zone I or II. 
GA is the strongest risk factor for developing severe ROP. In cryotherapy for ROP study (CRYO-ROP), younger age was associated with the development of threshold ROP ${ }^{21}$. This finding has been replicated in other studies ${ }^{22-25}$. Lower GA was a common risk factor among various studies to be associated with recurrence after successful initial treatment ${ }^{12,26,27}$. Infants with lower GA are more ill, have a higher grade of retinopathy, and additionally lower capacity to produce anti-oxidant enzymes. Our result implies that GA under 32 weeks imposes a $4.4 \%$ increased possibility of primary treatment failure. Therefore it is crucial to maintain vigorous follow-up examination in the early phase after therapy to detect signs of treatment failure in these subsets of infants.

Our results demonstrate that plus disease, defined as vascular tortuosity and dilation, is associated with a $4 \%$ increase in the prevalence of treatment failure. Excessive signaling through VEGF-VEGFR2 is involved in the features of plus disease. Therefore, regulation of VEGFR2 signaling through anti-VEGF treatment combats this condition and prevents progressive neovascularization. On the other hand presence of plus disease indicates a more severe form of the disease ${ }^{2}$. Additionally, primary failure indicates an overabundance of VEGF, which is not completely controlled with single-dose treatment. So, it is rational that those infants suffering from a more severe form of the disease are prone to treatment failure and might require further therapy throughout the course of the disease. However, $99.5 \%$ of infants in our study had plus disease. This issue underscores the necessity for a standard grading scale of vascular abnormality in ROP. Recently, efforts have been made to apply vascular severity scores for patients with ROP ${ }^{28-30}$. These investigations showed variability in plus disease. In fact, eyes with higher severity scores may be prone to unresponsiveness to treatment or recurrence. This hypothesis requires further prospective studies to evaluate objective vascular scores to differentiate the severity of plus disease and its association with treatment response.

Based on our findings, oxygen therapy is associated with a $4.5 \%$ increase in the prevalence of primary treatment failure. A historical trial published in 1956 found that the incidence of ROP is higher in infants treated with $>50 \%$ oxygen ${ }^{31}$. Additionally, the period of oxygen therapy, fluctuation in oxygen saturation, and mechanical ventilation are independent risk factors for the development of severe ROP ${ }^{32-34}$. Although lower oxygen saturation may decrease the incidence of severe ROP, an increase in mortality has been observed in BOOST II collaborative group study ${ }^{35}$. So the optimum root of oxygen delivery is still controversial, and due to the relatively small sample size for subgroup analysis of methods of oxygen therapy, our data do not have sufficient power to determine this detail.

Previous retrospective and observational studies define various risk factors for the prediction of recurrence of ROP after IVB-treatment. Previously reported risk factors for recurrent ROP after anti-VEGF therapy includes lower GA, lower BW, longer duration of hospitalization, extensive retinal neovascularization, supplemental oxygen requirement after treatment, and preretinal hemorrhage before treatment, as long as multiple bitrth. ${ }^{12,13,20,36}$. In the current study, we assessed the risk factors for recurrence of ROP after treatment with Bevacizumab. From 16 factors we assessed, lower birth weight, 
zone 1 pretreatment, history of intubation, anemia, and sepsis were associated with increasing recurrence chance in univariate analysis, while only intubation is significant in multivariable analysis.

Unlike the abovementioned studies, we did not find gestational age an independent risk factor of recurrence. Although, Earlier gestational age at initial treatment may show illness of these infants and had more severe retinopathy that required earlier treatment. Likely because 2 of 20 patients who suffered recurrence after IVB were in 34 weeks of gestational age. It implies that vigilant follow-up for IVB treated patients requires all treated patients independent of gestational age. Main ROP risk factors include low gestational age and birth weight; 37,38 in our study, we mentioned that maybe birth weight is a more independent risk factor that implies prematurity than gestational age. Moreover, the history of ARDS was marginally an insignificant risk factor. Lyu et al. reported an 11-fold increased risk of ROP recurrence in patients with a history of oxygen therapy. ${ }^{36}$

History of intubation and sepsis in infants implies more severe ocular hypoxia and higher oxygen requirements. Then, Systemic hypoxia during this period may exacerbate the retina's hypoxia and block retinal maturation, increasing the risk of recurrent neovascularization. Moreover, Zone 1 pretreatment implies a more aggressive nature of retinopathy which requires more vigilant follow-up.

Similar to previous studies on this subject, our study's limitations include its retrospective nature, data collection from a single institution as long as we did not perform fluorescein angiography in our recurrent cases. In order to accurately diagnose persistent disease or recurrence of ROP in IVB- treated ROP, the cautious approach is to done fluorescein angiography to confirm the extent of retinal vascularization. As a result, Our results cannot be generalized to all eyes with type 1 ROP, as only eyes with more aggressive forms of ROP whereby laser would be suboptimal or not possible were offered IVB in our series. On the other hand, a large sample size and being treated at the same hospital with standardized treatment protocols are significant strengths of the study.

Our results help incorporate risk factors into practice patterns and devise a plan for early detection of treatment failure and recurrence. Although over examination following treatment can prevent dreadful sequels of ROP, it is worthy of note that ROP examinations, despite their medical cost, can induce morbidity in neonates, including decreased oxygen saturation, increased heart rate, and apnea events. ${ }^{39}$ Attention to risk factors accompanied by special care to patterns of treatment failure, and recurrence, helps to achieve both objectives.

In Conclusion, intravitreal Bevacizumab is an effective treatment in inducing ROP regression, low rate of primary failure, but the effect may be transient in some cases. Post IVB treatment, recurrence can occur later in the course than with conventional laser therapy. The risk factor for predicting primary failure in our study is infants with younger age and plus disease who have a history of phototherapy and oxygen therapy. The risk factor predicting recurrence is a history of intubation. Future studies on the definition of primary failure, recurrence and screening criteria, treatment type recommendations, and time should be done. 


\section{Declarations}

\section{Acknowledgments}

Special thanks to Mehdi Yaseri PhD. for data analysis.

\section{Funding}

Not applicable.

\section{Competing interests}

The authors declare that they have no competing interests

\section{Availability of data and materials}

The datasets analyzed during the current study are available from the corresponding author on reasonable request.

\section{Code availability:}

Not applicable.

\section{Authors' contributions}

FB and HRE: Conception and design, Definition of intellectual content, Data Acquisition, Analysis and interpretation, Manuscript Review, Guarantor. KF and MH and MMB :Analysis and interpretation, Literature Search, Data Acquisition, Manuscript Preparation, Manuscript Editing, Manuscript Review. AA and ADF: Definition of intellectual content, Literature Search, Manuscript Review, consistent criticism. All authors read and approved the final manuscript and agree to be accountable for all aspects of the work in ensuring that questions related to the accuracy or integrity of any part of the work are appropriately investigated and resolved.

\section{Ethics approval and consent to participate}

Human subjects were included in this study. The ethics committee of eye research center, Farabi Eye Hospital, approved this study (https://ethics.research.ac.ir/IR.TUMS.FARABI.REC.1399.040). The study 
was conducted according to the tenets of the Declaration of Helsinki. Any procedure was done after providing parents with informed consent.

\section{Consent for publication}

Written informed consent was obtained from the patient's parents (that his fundus photographs were used in the Figue1) for publication of any accompanying images. A copy of the written consent is available for review by the Editor-in-Chief of this journal.

\section{References}

1. Gillbert C, Muhit M. Twenty years of childhood blindness: What have we learnt? Community Eye Heal J. 2008;21(67):46-47. Accessed December 16, 2020. https://www.ncbi.nlm.nih.gov/pmc/articles/PMC2580065/

2. Hartnett ME, Penn JS (2012) Mechanisms and Management of Retinopathy of Prematurity. N Engl J Med 367(26):2515-2526. doi:10.1056/NEJMra1208129

3. Good WV, Group ET (2004) for R of PC. Final results of the Early Treatment for Retinopathy of Prematurity (ETROP) randomized trial. Trans Am Ophthalmol Soc 102:233-250. https://pubmed.ncbi.nlm.nih.gov/15747762

4. Geloneck MM, Chuang AZ, Clark WL et al (2014) Refractive outcomes following bevacizumab monotherapy compared with conventional laser treatment: a randomized clinical trial. JAMA Ophthalmol 132(11):1327-1333. doi:10.1001/jamaophthalmol.2014.2772

5. Mintz-Hittner HA, Kennedy KA, Chuang AZ (2011) Efficacy of Intravitreal Bevacizumab for Stage $3+$ Retinopathy of Prematurity. N Engl J Med 364(7):603-615. doi:10.1056/NEJMoa1007374

6. Roohipoor R, Karkhaneh R, Riazi-Esfahani M et al (2018) Comparison of Intravitreal Bevacizumab and Laser Photocoagulation in the Treatment of Retinopathy of Prematurity. Ophthalmol Retin 2(9):942-948. doi:10.1016/j.oret.2018.01.017

7. Pertl L, Steinwender G, Mayer C et al (2015) A Systematic Review and Meta-Analysis on the Safety of Vascular Endothelial Growth Factor (VEGF) Inhibitors for the Treatment of Retinopathy of Prematurity. PLoS One 10(6):e0129383. doi:10.1371/journal.pone.0129383

8. Bazvand F, Pour EK, Gharehbaghi G et al (2020) Hypertension and ischemic stroke after aflibercept for retinopathy of prematurity. Int Med Case Rep J 13:243-247. doi:10.2147/IMCRJ.S258881

9. Bazvand F, Riazi-Esfahani H, Mirshahi A et al (2021) Ocular complications following intravitreal bevacizumab injection for retinopathy of prematurity and assessment of risk factors. Int J Retin Vitr 7(1):5. doi:10.1186/s40942-020-00276-3

10. Sankar MJ, Sankar J, Chandra P. Anti-vascular endothelial growth factor (VEGF) drugs for treatment of retinopathy of prematurity. Cochrane Database Syst Rev. 2018;2018(1). doi:10.1002/14651858.CD009734.pub3 
11. Martínez-Castellanos MA, González-H León A, Romo-Aguas JC, Gonzalez-Gonzalez LA (2020) A proposal of an algorithm for the diagnosis and treatment of recurrence or treatment failure of retinopathy of prematurity after anti-VEGF therapy based on a large case series. Graefe's Arch Clin Exp Ophthalmol = Albr von Graefes Arch fur Klin Exp Ophthalmol 258(4):767-772. doi:10.1007/s00417-020-04605-y

12. Mintz-Hittner HA, Geloneck MM, Chuang AZ (2016) Clinical Management of Recurrent Retinopathy of Prematurity after Intravitreal Bevacizumab Monotherapy. Ophthalmology 123(9):1845-1855. doi:10.1016/j.ophtha.2016.04.028

13. Ling KP, Liao PJ, Wang NK et al RATES AND RISK FACTORS FOR RECURRENCE OF RETINOPATHY OF PREMATURITY AFTER LASER OR INTRAVITREAL ANTI-VASCULAR ENDOTHELIAL GROWTH FACTOR MONOTHERAPY (2020) Retina 40(9):1793-1803. doi:10.1097/IAE.0000000000002663

14. Chen TA, Shields RA, Bodnar ZH, Callaway NF, Schachar IH, Moshfeghi DM (2019) A Spectrum of Regression Following Intravitreal Bevacizumab in Retinopathy of Prematurity. Am J Ophthalmol 198:63-69. doi:10.1016/j.ajo.2018.09.039

15. Karkhaneh R, Khodabande A, Riazi-Eafahani M et al (2016) Efficacy of intravitreal bevacizumab for zone-II retinopathy of prematurity. Acta Ophthalmol 94(6):e417-e420. doi:10.1111/aos.13008

16. Hajrasouliha AR, Garcia-Gonzales JM, Shapiro MJ, Yoon H, Blair MP (2017) Reactivation of Retinopathy of Prematurity Three Years After Treatment With Bevacizumab. Ophthalmic Surg Lasers Imaging Retina 48(3):255-259. doi:10.3928/23258160-20170301-10

17. Snyder LL, Garcia-Gonzalez JM, Shapiro MJ, Blair MP (2016) Very Late Reactivation of Retinopathy of Prematurity After Monotherapy With Intravitreal Bevacizumab. Ophthalmic Surg Lasers Imaging Retina 47(3):280-283. doi:10.3928/23258160-20160229-12

18. Hu J, Blair MP, Shapiro MJ, Lichtenstein SJ, Galasso JM, Kapur R (2012) Reactivation of retinopathy of prematurity after bevacizumab injection. Arch Ophthalmol (Chicago III 1960) 130(8):1000-1006. doi:10.1001/archophthalmol.2012.592

19. Campbell JP, Ataer-Cansizoglu E, Bolon-Canedo V et al (2016) Expert Diagnosis of Plus Disease in Retinopathy of Prematurity From Computer-Based Image Analysis. JAMA Ophthalmol 134(6):651657. doi:10.1001/jamaophthalmol.2016.0611

20. Chan JJT, Lam CPS, Kwok MKM et al (2016) Risk of recurrence of retinopathy of prematurity after initial intravitreal ranibizumab therapy. Sci Rep 6(1):1-7. doi:10.1038/srep27082

21. Schaffer DB, Palmer EA, Plotsky DF et al (1993) Prognostic Factors in the Natural Course of Retinopathy of Prematurity. Ophthalmology 100(2):230-237. doi:10.1016/S0161-6420(93)31665-9

22. Alajbegovic-Halimic J, Zvizdic D, Alimanovic-Halilovic E, Dodik I, Duvnjak S (2015) Risk Factors for Retinopathy of Prematurity in Premature Born Children. Med Arch (Sarajevo Bosnia Herzegovina) 69(6):409-413. doi:10.5455/medarh.2015.69.409-413

23. Allegaert K, Casteels I, Cossey V, Devlieger H (2003) Retinopathy of prematurity: Any difference in risk factors between a high and low risk population? Eur J Ophthalmol 13(9-10):784-788. doi:10.1177/1120672103013009-1009 
24. Chen YH, Lien RI, Tsai S et al (2015) Natural history of retinopathy of prematurity: Two-year outcomes of a prospective study. Retina 35(1):141-148. doi:10.1097/IAE.0000000000000270

25. Giapros V, Drougia A, Asproudis I, Theocharis P, Andronikou S (2011) Low gestational age and chronic lung disease are synergistic risk factors for retinopathy of prematurity. Early Hum Dev 87(10):653-657. doi:10.1016/j.earlhumdev.2011.05.003

26. Lyu J, Zhang Q, Chen C-LL et al (2017) Recurrence of Retinopathy of Prematurity After Intravitreal Ranibizumab Monotherapy: Timing and Risk Factors. Invest Ophthalmol Vis Sci 58(3):1719-1725. doi:10.1167/iovs.16-20680

27. Hu Q, Bai Y, Chen X, Huang L, Chen Y, Li X. Recurrence of Retinopathy of Prematurity in Zone II Stage 3 + after Ranibizumab Treatment: A Retrospective Study. J Ophthalmol. 2017;2017. doi:10.1155/2017/5078565

28. Choi RY, Brown JM, Kalpathy-Cramer J et al (2020) Variability in Plus Disease Identified Using a Deep Learning-Based Retinopathy of Prematurity Severity Scale. In: Ophthalmology Retina, vol 4. Elsevier Inc., pp 1016-1021. doi:10.1016/j.oret.2020.04.022

29. Taylor S, Brown JM, Gupta K et al (2019) Monitoring Disease Progression with a Quantitative Severity Scale for Retinopathy of Prematurity Using Deep Learning. JAMA Ophthalmol 137(9):10221028. doi:10.1001/jamaophthalmol.2019.2433

30. Campbell JP, Kim SJ, Brown JM et al (2020) Evaluation of a novel retinopathy of prematurity severity scale applied by clinicians and deep learning. Ophthalmology Published online October. doi:10.1016/j.ophtha.2020.10.025

31. KINSEY VE (1956) Retrolental fibroplasia; cooperative study of retrolental fibroplasia and the use of oxygen. AMA Arch Ophthalmol 56(4):481-543

32. Flynn JT, Bancalari E, Snyder ES et al (1992) A Cohort Study of Transcutaneous Oxygen Tension and the Incidence and Severity of Retinopathy of Prematurity. N Engl J Med 326(16):1050-1054. doi:10.1056/NEJM199204163261603

33. Cunningham S, Mclntosh N, Fleck BW, Elton RA (1995) Transcutaneous oxygen levels in retinopathy of prematurity. Lancet 346(8988):1464-1465. doi:10.1016/S0140-6736(95)92475-2

34. Bossi E, Koerner F, Flury B, Zulauf M (1984) Retinopathy of prematurity: a risk factor analysis with univariate and multivariate statistics. Helv Paediatr Acta 39(4):307-317

35. Oxygen Saturation and Outcomes in Preterm Infants (2013) N Engl J Med 368(22):2094-2104. doi:10.1056/nejmoa1302298

36. Lyu J, Zhang Q, Chen C-LL et al (2017) Recurrence of Retinopathy of Prematurity After Intravitreal Ranibizumab Monotherapy: Timing and Risk Factors. Invest Ophthalmol Vis Sci 58(3):1719-1725. doi:10.1167/iovs.16-20680

37. Darlow BA, Hutchinson JL, Henderson-Smart DJ, Donoghue DA, Simpson JM, Evans NJ (2005) Prenatal risk factors for severe retinopathy of prematurity among very preterm infants of the Australian and New Zealand Neonatal Network. Pediatrics 115(4):990-996. doi:10.1542/peds.20041309 
38. Zarei M, Bazvand F, Ebrahimiadib N et al (2019) Prevalence and Risk Factors of Retinopathy of Prematurity in Iran. J Ophthalmic Vis Res 14(3):291-298. doi:10.18502/jovr.v14i3.4785

39. Mitchell AJ, Green A, Jeffs DA, Roberson PK (2011) Physiologic effects of retinopathy of prematurity screening examinations. Adv Neonatal Care 11(4):291-297. doi:10.1097/ANC.0b013e318225a332

\section{Tables}

\section{Table 1}

Baseline and demographic characteristics of Infants 


\begin{tabular}{|c|c|c|c|c|c|c|c|}
\hline & \multicolumn{6}{|c|}{ regression } \\
\hline & & \multicolumn{2}{|l|}{ Total } & \multicolumn{2}{|l|}{ yes } & \multicolumn{2}{|l|}{ no } \\
\hline & & Count & percent $\%$ & Count & percent $\%$ & Count & percent $\%$ \\
\hline \multirow[t]{2}{*}{ Eye } & OD & 431 & $(100.0 \%)$ & 413 & $(95.8 \%)$ & 18 & $(4.2 \%)$ \\
\hline & os & 434 & $(100.0 \%)$ & 417 & $(96.1 \%)$ & 17 & $(3.9 \%)$ \\
\hline \multirow[t]{2}{*}{ Gender } & male & 496 & $(100.0 \%)$ & 481 & $(97.0 \%)$ & 15 & $(3.0 \%)$ \\
\hline & female & 369 & $(100.0 \%)$ & 349 & $(94.6 \%)$ & 20 & $(5.4 \%)$ \\
\hline \multirow[t]{2}{*}{ Zone pretreatment } & 1 & 187 & $(100.0 \%)$ & 169 & $(90.4 \%)$ & 18 & $(9.6 \%)$ \\
\hline & 2 & 678 & $(100.0 \%)$ & 661 & $(97.5 \%)$ & 17 & $(2.5 \%)$ \\
\hline \multirow[t]{2}{*}{ Plus } & yes & 861 & $(100.0 \%)$ & 826 & $(95.9 \%)$ & 35 & $(4.1 \%)$ \\
\hline & no & 4 & $(100.0 \%)$ & 4 & $(100.0 \%)$ & 0 & $(0.0 \%)$ \\
\hline \multirow[t]{2}{*}{ NVI } & yes & 54 & $(100.0 \%)$ & 48 & $(88.9 \%)$ & 6 & $(11.1 \%)$ \\
\hline & no & 811 & $(100.0 \%)$ & 782 & $(96.4 \%)$ & 29 & $(3.6 \%)$ \\
\hline \multirow[t]{2}{*}{ Twin } & yes & 210 & $(100.0 \%)$ & 204 & $(97.1 \%)$ & 6 & $(2.9 \%)$ \\
\hline & no & 655 & $(100.0 \%)$ & 626 & $(95.6 \%)$ & 29 & $(4.4 \%)$ \\
\hline \multirow[t]{2}{*}{02 therapy } & yes & 764 & $(100.0 \%)$ & 729 & $(95.4 \%)$ & 35 & $(4.6 \%)$ \\
\hline & no & 99 & $(100.0 \%)$ & 99 & $(100.0 \%)$ & 0 & $(0.0 \%)$ \\
\hline \multirow[t]{2}{*}{ Intubation } & yes & 348 & $(100.0 \%)$ & 333 & $(95.7 \%)$ & 15 & $(4.3 \%)$ \\
\hline & no & 515 & $(100.0 \%)$ & 495 & $(96.1 \%)$ & 20 & $(3.9 \%)$ \\
\hline \multirow[t]{2}{*}{ Transfusion } & yes & 491 & $(100.0 \%)$ & 470 & $(95.7 \%)$ & 21 & $(4.3 \%)$ \\
\hline & no & 372 & $(100.0 \%)$ & 358 & $(96.2 \%)$ & 14 & $(3.8 \%)$ \\
\hline \multirow[t]{2}{*}{ IVH } & yes & 62 & $(100.0 \%)$ & 59 & $(95.2 \%)$ & 3 & $(4.8 \%)$ \\
\hline & no & 801 & $(100.0 \%)$ & 769 & $(96.0 \%)$ & 32 & $(4.0 \%)$ \\
\hline \multirow[t]{2}{*}{ Sepsis } & yes & 340 & $(100.0 \%)$ & 327 & $(96.2 \%)$ & 13 & $(3.8 \%)$ \\
\hline & no & 523 & $(100.0 \%)$ & 501 & $(95.8 \%)$ & 22 & $(4.2 \%)$ \\
\hline \multirow[t]{2}{*}{ Phototherapy } & yes & 572 & $(100.0 \%)$ & 541 & $(94.6 \%)$ & 31 & $(5.4 \%)$ \\
\hline & no & 291 & $(100.0 \%)$ & 287 & $(98.6 \%)$ & 4 & $(1.4 \%)$ \\
\hline \multirow[t]{2}{*}{ Anemia } & yes & 76 & $(100.0 \%)$ & 74 & $(97.4 \%)$ & 2 & $(2.6 \%)$ \\
\hline & no & 787 & $(100.0 \%)$ & 754 & (95.8\%) & 33 & $(4.2 \%)$ \\
\hline
\end{tabular}


ARDS

$\begin{array}{lllllll}\text { yes } & 457 & (100.0 \%) & 436 & (95.4 \%) & 21 & (4.6 \%) \\ \text { no } & 406 & (100.0 \%) & 392 & (96.6 \%) & 14 & (3.4 \%)\end{array}$

ARDS: acute respiratory distress syndrome; IVH: Intraventricular hemorrhage; NVI: neovascularization of iris

\section{Table2}

Prevalence ratio of risk factors associated with primary treatment failure following intravitreal Bevacizumab to treat aggressive posterior retinopathy of prematurity 


\begin{tabular}{|c|c|c|c|c|c|c|c|c|}
\hline \multirow[t]{2}{*}{ Parameter } & \multirow[t]{2}{*}{ Level } & \multirow[t]{2}{*}{ Total } & \multicolumn{2}{|c|}{ Regression } & \multirow[t]{2}{*}{ PR } & \multicolumn{2}{|l|}{$95 \% \mathrm{Cl}$} & \multirow[t]{2}{*}{$\mathbf{P}$} \\
\hline & & & No & Yes & & Lower & Upper & \\
\hline \multirow[t]{2}{*}{ Eye } & OD & $\begin{array}{l}431 \\
(49.8 \%)\end{array}$ & $\begin{array}{l}413 \\
(95.8 \%)\end{array}$ & $\begin{array}{l}18 \\
(4.2 \%)\end{array}$ & 1.002 & 0.998 & 1.007 & 0.316 \\
\hline & os & $\begin{array}{l}434 \\
(50.2 \%)\end{array}$ & $\begin{array}{l}417 \\
(96.1 \%)\end{array}$ & $\begin{array}{l}17 \\
(3.9 \%)\end{array}$ & & & & \\
\hline \multirow[t]{2}{*}{ Gender } & male & $\begin{array}{l}496 \\
(57.3 \%)\end{array}$ & $\begin{array}{l}481 \\
(97.0 \%)\end{array}$ & $\begin{array}{l}15 \\
(3.0 \%)\end{array}$ & 0.978 & 0.943 & 1.014 & 0.230 \\
\hline & female & $\begin{array}{l}369 \\
(42.7 \%)\end{array}$ & $\begin{array}{l}349 \\
(94.6 \%)\end{array}$ & $\begin{array}{l}20 \\
(5.4 \%)\end{array}$ & & & & \\
\hline \multirow[t]{2}{*}{$\begin{array}{l}\text { Zone } \\
\text { pretreatment }\end{array}$} & 1 & $\begin{array}{l}187 \\
(21.6 \%)\end{array}$ & $\begin{array}{l}169 \\
(90.4 \%)\end{array}$ & $\begin{array}{l}18 \\
(9.6 \%)\end{array}$ & 1.029 & 0.995 & 1.064 & 0.092 \\
\hline & 2 & $\begin{array}{l}678 \\
(78.4 \%)\end{array}$ & $\begin{array}{l}661 \\
(97.5 \%)\end{array}$ & $\begin{array}{l}17 \\
(2.5 \%)\end{array}$ & & & & \\
\hline \multirow[t]{2}{*}{ Plus } & yes & $\begin{array}{l}861 \\
(99.5 \%)\end{array}$ & $\begin{array}{l}826 \\
(95.9 \%)\end{array}$ & $\begin{array}{l}35 \\
(4.1 \%)\end{array}$ & 1.040 & 1.022 & 1.058 & $<0.001 *$ \\
\hline & no & $4(0.5 \%)$ & $\begin{array}{l}4 \\
(100.0 \%)\end{array}$ & $\begin{array}{l}0 \\
(0.0 \%)\end{array}$ & & & & \\
\hline \multirow[t]{2}{*}{ NVI } & yes & $\begin{array}{l}54 \\
(6.2 \%)\end{array}$ & $\begin{array}{l}48 \\
(88.9 \%)\end{array}$ & $\begin{array}{l}6 \\
(11.1 \%)\end{array}$ & 1.074 & 0.964 & 1.196 & 0.198 \\
\hline & no & $\begin{array}{l}811 \\
(93.8 \%)\end{array}$ & $\begin{array}{l}782 \\
(96.4 \%)\end{array}$ & $\begin{array}{l}29 \\
(3.6 \%)\end{array}$ & & & & \\
\hline \multirow[t]{2}{*}{ Twin } & yes & $\begin{array}{l}210 \\
(24.3 \%)\end{array}$ & $\begin{array}{l}204 \\
(97.1 \%)\end{array}$ & $\begin{array}{l}6 \\
(2.9 \%)\end{array}$ & 0.985 & 0.950 & 1.022 & 0.430 \\
\hline & no & $\begin{array}{l}655 \\
(75.7 \%)\end{array}$ & $\begin{array}{l}626 \\
(95.6 \%)\end{array}$ & $\begin{array}{l}29 \\
(4.4 \%)\end{array}$ & & & & \\
\hline \multirow[t]{2}{*}{$\begin{array}{l}\text { Oxygen } \\
\text { therapy }\end{array}$} & yes & $\begin{array}{l}764 \\
(88.5 \%)\end{array}$ & $\begin{array}{l}729 \\
(95.4 \%)\end{array}$ & $\begin{array}{l}35 \\
(4.6 \%)\end{array}$ & 1.045 & 1.025 & 1.065 & $<0.001$ * \\
\hline & no & $\begin{array}{l}99 \\
(11.5 \%)\end{array}$ & $\begin{array}{l}99 \\
(100.0 \%)\end{array}$ & $\begin{array}{l}0 \\
(0.0 \%)\end{array}$ & & & & \\
\hline \multirow[t]{2}{*}{ Intubation } & yes & $\begin{array}{l}348 \\
(40.3 \%)\end{array}$ & $\begin{array}{l}333 \\
(95.7 \%)\end{array}$ & $\begin{array}{l}15 \\
(4.3 \%)\end{array}$ & 1.005 & 0.969 & 1.041 & 0.803 \\
\hline & no & $\begin{array}{l}515 \\
(59.7 \%)\end{array}$ & $\begin{array}{l}495 \\
(96.1 \%)\end{array}$ & $\begin{array}{l}20 \\
(3.9 \%)\end{array}$ & & & & \\
\hline \multirow[t]{2}{*}{ Transfusion } & yes & $\begin{array}{l}491 \\
(56.9 \%)\end{array}$ & $\begin{array}{l}470 \\
(95.7 \%)\end{array}$ & $\begin{array}{l}21 \\
(4.3 \%)\end{array}$ & 1.006 & 0.972 & 1.042 & 0.736 \\
\hline & no & $\begin{array}{l}372 \\
(43.1 \%)\end{array}$ & $\begin{array}{l}358 \\
(96.2 \%)\end{array}$ & $\begin{array}{l}14 \\
(3.8 \%)\end{array}$ & & & & \\
\hline
\end{tabular}




\begin{tabular}{|c|c|c|c|c|c|c|c|c|}
\hline IVH & yes & $\begin{array}{l}62 \\
(7.2 \%)\end{array}$ & $\begin{array}{l}59 \\
(95.2 \%)\end{array}$ & $\begin{array}{l}3 \\
(4.8 \%)\end{array}$ & 1.009 & 0.943 & 1.080 & 0.789 \\
\hline & no & $\begin{array}{l}801 \\
(92.8 \%)\end{array}$ & $\begin{array}{l}769 \\
(96.0 \%)\end{array}$ & $\begin{array}{l}32 \\
(4.0 \%)\end{array}$ & & & & \\
\hline \multirow[t]{2}{*}{ Sepsis } & yes & $\begin{array}{l}340 \\
(39.4 \%)\end{array}$ & $\begin{array}{l}327 \\
(96.2 \%)\end{array}$ & $\begin{array}{l}13 \\
(3.8 \%)\end{array}$ & 0.997 & 0.962 & 1.032 & 0.846 \\
\hline & no & $\begin{array}{l}523 \\
(60.6 \%)\end{array}$ & $\begin{array}{l}501 \\
(95.8 \%)\end{array}$ & $\begin{array}{l}22 \\
(4.2 \%)\end{array}$ & & & & \\
\hline \multirow[t]{2}{*}{ Phototherapy } & yes & $\begin{array}{l}572 \\
(66.3 \%)\end{array}$ & $\begin{array}{l}541 \\
(94.6 \%)\end{array}$ & $\begin{array}{l}31 \\
(5.4 \%)\end{array}$ & 1.039 & 1.008 & 1.071 & $0.014^{*}$ \\
\hline & no & $\begin{array}{l}291 \\
(33.7 \%)\end{array}$ & $\begin{array}{l}287 \\
(98.6 \%)\end{array}$ & $\begin{array}{l}4 \\
(1.4 \%)\end{array}$ & & & & \\
\hline \multirow[t]{2}{*}{ Anemia } & yes & $\begin{array}{l}76 \\
(8.8 \%)\end{array}$ & $\begin{array}{l}74 \\
(97.4 \%)\end{array}$ & $\begin{array}{l}2 \\
(2.6 \%)\end{array}$ & 0.985 & 0.935 & 1.037 & 0.570 \\
\hline & no & $\begin{array}{l}787 \\
(91.2 \%)\end{array}$ & $\begin{array}{l}754 \\
(95.8 \%)\end{array}$ & $\begin{array}{l}33 \\
(4.2 \%)\end{array}$ & & & & \\
\hline \multirow[t]{2}{*}{ ARDS } & yes & $\begin{array}{l}457 \\
(53.0 \%)\end{array}$ & $\begin{array}{l}436 \\
(95.4 \%)\end{array}$ & $\begin{array}{l}21 \\
(4.6 \%)\end{array}$ & 1.012 & 0.977 & 1.048 & 0.503 \\
\hline & no & $\begin{array}{l}406 \\
(47.0 \%)\end{array}$ & $\begin{array}{l}392 \\
(96.6 \%)\end{array}$ & $\begin{array}{l}14 \\
(3.4 \%)\end{array}$ & & & & \\
\hline
\end{tabular}

ARDS: acute respiratory distress syndrome; IVH: Intraventricular hemorrhage; NVI: neovascularization of iris, PR: prevalence ratio, P: $p$ value tested by.., *: statistically significant.

\section{Table 3}

Multiple variables regression analysis of parameters associated with primary treatment failure following intravitreal Bevacizumab to treat type 1 retinopathy of prematurity 


\begin{tabular}{|c|c|c|c|c|c|}
\hline \multirow[t]{2}{*}{ Parameter } & \multirow[t]{2}{*}{ Level } & \multirow[t]{2}{*}{ PR } & \multicolumn{2}{|l|}{$95 \% \mathrm{Cl}$} & \multirow[t]{2}{*}{$P$ value } \\
\hline & & & Lower & Upper & \\
\hline \multirow[t]{2}{*}{ Zone pretreatment } & 1 & 1.029 & 0.995 & 1.064 & 0.189 \\
\hline & 2 & & & & \\
\hline \multirow[t]{2}{*}{ Plus } & yes & 1.040 & 1.022 & 1.058 & $<0.001^{*}$ \\
\hline & no & & & & \\
\hline \multirow[t]{2}{*}{ NVI } & yes & 1.074 & 0.964 & 1.196 & 0.218 \\
\hline & no & & & & \\
\hline \multirow[t]{2}{*}{ Oxygen therapy } & yes & 1.045 & 1.025 & 1.065 & $<0.001^{*}$ \\
\hline & no & & & & \\
\hline \multirow[t]{2}{*}{ Phototherapy } & yes & 1.039 & 1.008 & 1.071 & $0.020^{*}$ \\
\hline & no & & & & \\
\hline \multirow[t]{2}{*}{ GA } & $<32 w$ & 1.049 & 1.023 & 1.077 & $<0.001 *$ \\
\hline & $32-34 w$ & 1.027 & 0.989 & 1.067 & 0.159 \\
\hline
\end{tabular}

PR: prevalence ratio; NVI: neovascularization of iris; GA: gestational age, *: statistically significant.

\section{Table 4}

Demographic data of patients with recurrence of retinopathy of prematurity 


\begin{tabular}{|c|c|c|c|c|c|c|}
\hline $\begin{array}{l}\text { GA } \\
\text { (weeks) }\end{array}$ & $\begin{array}{l}\text { BW } \\
\text { (grams) }\end{array}$ & Gender & $\begin{array}{l}\text { Time first } \\
\text { treatment } \\
\text { from birth } \\
\text { date } \\
\text { (days) }\end{array}$ & $\begin{array}{l}\text { Laterality } \\
\text { of } \\
\text { recurrence }\end{array}$ & $\begin{array}{l}\text { Severity of } \\
\text { ROP at the } \\
\text { time of } \\
\text { first } \\
\text { treatment }\end{array}$ & Retreatment \\
\hline
\end{tabular}

\begin{tabular}{|c|c|c|c|c|c|c|c|}
\hline Case 1 & 30 & 670 & Female & 74 & Bilateral & Z1-S3-Plus & IVB \\
\hline Case 2 & 34 & 1400 & Male & 51 & Unilateral & $\begin{array}{l}\text { Z1-S3- } \\
\text { Plus }\end{array}$ & Laser \\
\hline Case3 & 27 & 1220 & Male & 48 & Unilateral & $\begin{array}{l}\text { Z2-S3- } \\
\text { Plus }\end{array}$ & Laser \\
\hline Case4 & 28 & 900 & Female & 124 & Bilateral & Z2-S3-Plus & Laser \\
\hline Case5 & 26 & 700 & Female & 53 & Bilateral & Z2-S3-Plus & IVB \\
\hline Case6 & 30 & 1300 & Male & 34 & Bilateral & Z1-S3-Plus & Laser \\
\hline Case7 & 22 & 815 & Female & 67 & Unilateral & Z1-S3-Plus & IVB \\
\hline Case8 & 26 & 820 & Female & 73 & Bilateral & Z2-S3-Plus & Laser \\
\hline Case9 & 28 & 830 & Female & 50 & Bilateral & Z2-S3-Plus & Laser \\
\hline Case10 & 27 & 700 & Female & 54 & Bilateral & $\begin{array}{l}\text { Z2-S3- } \\
\text { Plus-NVI }\end{array}$ & Laser \\
\hline Case11 & 28 & 1120 & Male & 38 & Bilateral & Z2-S3-Plus & Laser \\
\hline Case12 & 29 & 1360 & Female & 27 & Bilateral & Z2-S3-Plus & Laser \\
\hline Case13 & 34 & 2010 & Female & 34 & Unilateral & Z2-S3-Plus & Laser \\
\hline Case14 & 31 & 1600 & Male & 76 & Unilateral & Z2-S3-Plus & Laser \\
\hline Case15 & 25 & 720 & Male & 71 & Bilateral & Z1-S3-Plus & Laser \\
\hline \multirow[t]{2}{*}{ Case16 } & 26 & 930 & Female & 61 & Bilateral & Z2-S3-Plus & Laser OD \\
\hline & & & & & & & $\begin{array}{l}\text { Laser and } \\
\text { lensectomy } \\
\text { OS }\end{array}$ \\
\hline Case17 & 28 & 980 & Male & 57 & Bilateral & Z1-S3-Plus & Laser \\
\hline Case18 & 27 & 1100 & Male & 61 & Unilateral & Z2-S3-Plus & Laser \\
\hline Case19 & 26 & 960 & Female & 45 & Unilateral & $\begin{array}{l}\text { Z1-S3- } \\
\text { Plus-NVI }\end{array}$ & IVB \\
\hline Case20 & 26 & 620 & Bilateral & $\begin{array}{l}\text { OD:77, } \\
\text { OS:53 }\end{array}$ & Bilateral & Z2-S3-Plus & IVB \\
\hline
\end{tabular}

GA: gestational age, BW: birth weight, Z: zone, S: stage, NVI: neovascularization iris, IVB: intravitreal Bevacizumab 
Table 5

Univariate Analysis of Risk Factors for Recurrent ROP following IVB 


\begin{tabular}{|c|c|c|c|c|c|c|c|}
\hline & & \multicolumn{2}{|c|}{ Recurrence } & \multirow[t]{2}{*}{ HR } & \multicolumn{2}{|c|}{$95 \% \mathrm{Cl}$} & \multirow[t]{2}{*}{$\mathbf{P}$} \\
\hline & & Yes & No & & Lower & Upper & \\
\hline \multirow[t]{4}{*}{ GA } & $\begin{array}{l}\text { Mean } \pm \\
\text { SD }\end{array}$ & $28 \pm 2$ & $28 \pm 2$ & 0.90 & 0.76 & 1.07 & 0.237 \\
\hline & $<=30$ & $\begin{array}{l}30 \\
(5.1 \%)\end{array}$ & $\begin{array}{l}556 \\
(94.9 \%)\end{array}$ & 0.26 & 0.06 & 1.09 & 0.065 \\
\hline & $31-33$ & $1(1.1 \%)$ & $\begin{array}{l}93 \\
(98.9 \%)\end{array}$ & 0.06 & 0.01 & 0.61 & 0.018 \\
\hline & $34+$ & $\begin{array}{l}2 \\
(18.2 \%)\end{array}$ & $9(81.8 \%)$ & ref & & & \\
\hline \multirow[t]{4}{*}{ BW } & $\begin{array}{l}\text { Mean } \pm \\
\text { SD }\end{array}$ & $\begin{array}{l}983 \pm \\
319\end{array}$ & $\begin{array}{l}1129 \pm \\
314\end{array}$ & $0.83^{\star}$ & 0.72 & 0.96 & 0.013 \\
\hline & $<=1000$ & $\begin{array}{l}22 \\
(6.9 \%)\end{array}$ & $\begin{array}{l}295 \\
(93.1 \%)\end{array}$ & 2.06 & 0.48 & 8.77 & 0.327 \\
\hline & $\begin{array}{l}1001- \\
1500\end{array}$ & $9(2.9 \%)$ & $\begin{array}{l}302 \\
(97.1 \%)\end{array}$ & 0.89 & 0.19 & 4.10 & 0.876 \\
\hline & $1501+$ & $2(3.2 \%)$ & $\begin{array}{l}61 \\
(96.8 \%)\end{array}$ & ref & & & \\
\hline $\begin{array}{l}\text { Time first treatment } \\
\text { day }\end{array}$ & $\begin{array}{l}\text { Mean } \pm \\
\text { SD }\end{array}$ & $59 \pm 22$ & $58 \pm 19$ & 1.00 & 0.98 & 1.02 & 0.884 \\
\hline Time regression & $\begin{array}{l}\text { Mean } \pm \\
\text { SD }\end{array}$ & $14 \pm 8$ & $14 \pm 10$ & 1.00 & 0.96 & 1.04 & 0.959 \\
\hline \multirow[t]{2}{*}{ eye } & OD & $\begin{array}{l}18 \\
(5.2 \%)\end{array}$ & $\begin{array}{l}329 \\
(94.8 \%)\end{array}$ & 1.21 & 0.61 & 2.40 & 0.589 \\
\hline & os & $\begin{array}{l}15 \\
(4.3 \%)\end{array}$ & $\begin{array}{l}335 \\
(95.7 \%)\end{array}$ & ref & & & \\
\hline \multirow[t]{2}{*}{ Zone pretreatment } & 1 & $\begin{array}{l}13 \\
(9.4 \%)\end{array}$ & $\begin{array}{l}126 \\
(90.6 \%)\end{array}$ & 2.59 & 1.29 & 5.21 & $0.008^{*}$ \\
\hline & 2 & $\begin{array}{l}20 \\
(3.6 \%)\end{array}$ & $\begin{array}{l}538 \\
(96.4 \%)\end{array}$ & ref & & & \\
\hline \multirow[t]{2}{*}{ NVI } & yes & $3(7.5 \%)$ & $\begin{array}{l}37 \\
(92.5 \%)\end{array}$ & 1.54 & 0.47 & 5.05 & 0.476 \\
\hline & no & $\begin{array}{l}30 \\
(4.6 \%)\end{array}$ & $\begin{array}{l}627 \\
(95.4 \%)\end{array}$ & ref & & & \\
\hline \multirow[t]{2}{*}{ Twin } & yes & $7(4.3 \%)$ & $\begin{array}{l}157 \\
(95.7 \%)\end{array}$ & 0.86 & 0.38 & 1.99 & 0.732 \\
\hline & no & $\begin{array}{l}26 \\
(4.9 \%)\end{array}$ & $\begin{array}{l}507 \\
(95.1 \%)\end{array}$ & ref & & & \\
\hline
\end{tabular}




\begin{tabular}{|c|c|c|c|c|c|c|c|}
\hline \multirow[t]{2}{*}{ Oxygen therapy } & yes & $\begin{array}{l}33 \\
(5.4 \%)\end{array}$ & $\begin{array}{l}579 \\
(94.6 \%)\end{array}$ & 24.53 & 0.26 & 2330.13 & 0.168 \\
\hline & no & $0(0.0 \%)$ & $\begin{array}{l}83 \\
(100.0 \%)\end{array}$ & ref & & & \\
\hline \multirow[t]{2}{*}{ Intubation } & yes & $\begin{array}{l}26 \\
(9.1 \%)\end{array}$ & $\begin{array}{l}259 \\
(90.9 \%)\end{array}$ & 5.38 & 2.34 & 12.40 & $<0.001^{*}$ \\
\hline & no & $7(1.7 \%)$ & $\begin{array}{l}403 \\
(98.3 \%)\end{array}$ & ref & & & \\
\hline \multirow[t]{2}{*}{ Transfusion } & yes & $\begin{array}{l}17 \\
(4.3 \%)\end{array}$ & $\begin{array}{l}377 \\
(95.7 \%)\end{array}$ & 0.79 & 0.40 & 1.56 & 0.493 \\
\hline & no & $\begin{array}{l}16 \\
(5.3 \%)\end{array}$ & $\begin{array}{l}285 \\
(94.7 \%)\end{array}$ & ref & & & \\
\hline \multirow[t]{2}{*}{ IVH } & yes & $4(8.5 \%)$ & $\begin{array}{l}43 \\
(91.5 \%)\end{array}$ & 1.93 & 0.68 & 5.49 & 0.218 \\
\hline & no & $\begin{array}{l}29 \\
(4.5 \%)\end{array}$ & $\begin{array}{l}619 \\
(95.5 \%)\end{array}$ & ref & & & \\
\hline \multirow[t]{2}{*}{ Sepsis } & yes & $\begin{array}{l}21 \\
(7.6 \%)\end{array}$ & $\begin{array}{l}257 \\
(92.4 \%)\end{array}$ & 2.65 & 1.30 & 5.39 & $0.007^{\star}$ \\
\hline & no & $\begin{array}{l}12 \\
(2.9 \%)\end{array}$ & $\begin{array}{l}405 \\
(97.1 \%)\end{array}$ & ref & & & \\
\hline \multirow[t]{2}{*}{ Phototherapy } & yes & $\begin{array}{l}23 \\
(5.0 \%)\end{array}$ & $\begin{array}{l}435 \\
(95.0 \%)\end{array}$ & 1.21 & 0.58 & 2.54 & 0.614 \\
\hline & no & $\begin{array}{l}10 \\
(4.2 \%)\end{array}$ & $\begin{array}{l}227 \\
(95.8 \%)\end{array}$ & ref & & & \\
\hline \multirow[t]{2}{*}{ Anemia } & yes & $\begin{array}{l}10 \\
(17.5 \%)\end{array}$ & $\begin{array}{l}47 \\
(82.5 \%)\end{array}$ & 5.14 & 2.44 & 10.80 & $<0.001^{*}$ \\
\hline & no & $\begin{array}{l}23 \\
(3.6 \%)\end{array}$ & $\begin{array}{l}615 \\
(96.4 \%)\end{array}$ & ref & & & \\
\hline \multirow[t]{2}{*}{ ARDS } & yes & $\begin{array}{l}13 \\
(3.4 \%)\end{array}$ & $\begin{array}{l}369 \\
(96.6 \%)\end{array}$ & 0.53 & 0.27 & 1.07 & 0.078 \\
\hline & no & $\begin{array}{l}20 \\
(6.4 \%)\end{array}$ & $\begin{array}{l}293 \\
(93.6 \%)\end{array}$ & ref & & & \\
\hline
\end{tabular}

ARDS: acute respiratory distress syndrome; IVH: Intraventricular hemorrhage; NVI: neovascularization of iris, HR: Hazard ratio, P: p value tested, *: statistically significant.

Table 6

Multiple variables regression analysis of parameters associated with recurrence following intravitreal Bevacizumab to treat type 1 retinopathy of prematurity 


\begin{tabular}{|c|c|c|c|c|c|}
\hline \multirow[t]{2}{*}{ Parameter } & \multirow[t]{2}{*}{ Level } & \multirow[t]{2}{*}{ aHR } & \multicolumn{2}{|l|}{$95 \% \mathrm{Cl}$} & \multirow[t]{2}{*}{$P$ value } \\
\hline & & & Lower & Upper & \\
\hline \multirow[t]{2}{*}{ Zone pretreatment } & 1 & 1.87 & 0.91 & 3.86 & 0.089 \\
\hline & 2 & 1 & & & \\
\hline \multirow[t]{2}{*}{ ARDS } & yes & 0.73 & 0.32 & 1.70 & 0.470 \\
\hline & no & 1 & & & \\
\hline \multirow[t]{2}{*}{ anemia } & yes & 2.12 & 0.81 & 5.58 & 0.126 \\
\hline & no & 1 & & & \\
\hline \multirow[t]{2}{*}{ sepsis } & yes & 1.44 & 0.65 & 3.18 & 0.371 \\
\hline & no & 1 & & & \\
\hline \multirow[t]{2}{*}{ Intubation } & yes & 3.70 & 1.50 & 9.11 & $0.004^{*}$ \\
\hline & no & 1 & & & \\
\hline \multirow[t]{3}{*}{ GA } & $<32 w$ & 0.98 & 0.83 & 1.17 & 0.854 \\
\hline & $32-34 w$ & & & & \\
\hline & $>34 w$ & & & & \\
\hline
\end{tabular}

HR: hazard ratio;; GA: gestational age, *: statistically significant 